\title{
Library use by patients in an English maximum security hospital
}

\author{
John Milton, ${ }^{1}$ Rosemary Ruck ${ }^{1}$
}

The Psychiatrist (2013), 37, 188-191, doi: 10.1192/pb.bp.112.039420

${ }^{1}$ Rampton Hospital, Nottinghamshire Healthcare NHS Trust

Correspondence to John Milton (John.Milton@nottshc.nhs.uk)

First received 22 Mar 2012, final revision 20 Nov 2012, accepted 9 Jan 2013

\begin{abstract}
Aims and method Scant clinical attention is usually paid to (a) forensic patients' reading interests or (b) the potential that library services may offer in providing information and therapy to patients. We undertook a cross-sectional service evaluation of patients' library attendance and use at Rampton high secure hospital in a 12-month period between July 2009 and June 2010.
\end{abstract}

Results We collected information for 326 patients across all 28 wards. Almost $79 \%$ used the library service in some way, 66\% borrowing music, 67\% borrowing books and some borrowing both. Factual books were borrowed more than fiction, with graphic novels, talking books and self-help books about mental disorder all proving popular.

Clinical implications Reading and library use should be considered by clinicians in terms of the positive impact of improving literacy to enhance wider recovery, in relation to the impact of illness and medication effects on reading ability and the potential for providing health-related messages, illness education and reading therapy.

Declaration of interest None.
Rampton Hospital is one of three English high secure hospitals providing in-patient treatment for approximately 330 people with psychosis, personality disorder and intellectual disability (also known as learning disability in UK health services) and exhibiting high-risk behaviour (such as violence or sexual offending). Services are configured into five discrete units either by broad diagnostic categories or by gender. There is a mental illness service (patients $n=126$ in January 2011), a learning disability service $(n=47)$, a women's service (for psychosis, intellectual disability and personality disorder, $n=44$ ), two personality disorder services for men (the generic personality disorder service, $n=58$ ), and the Peaks unit (formerly the dangerous and severe personality disorder unit, $n=51$ ). Patients usually receive treatment at Rampton Hospital over several years. In addition to core biopsychosocial interventions, the appropriate use of leisure time and enhancing education potential is important within wider recovery.

Patients are able to borrow books and music at an onsite hospital library, sourced via a local public library (supported by Nottinghamshire County Library Services). The hospital librarian runs the library as part of our therapy and education department. These librarians also have informal links and meet regularly with other secure service librarians from prisons, local and national hospital secure units. Patients at Rampton Hospital are registered with the library on admission. All wards have a weekly, timetabled visit to the library, although this relies on staff availability to escort the patients there. Staff can also join the library. There are around 6000 books available, covering a variety of fiction and non-fiction areas as well as a range of music (available mainly as CDs). Different reading styles are catered for such as talking books, 'quick reads' (simplified text) and graphic novels (narrative works where a story is conveyed using sequential art, often similar to a traditional comic format). Patients can request non-stock items through the county library system. Patients can borrow up to 12 books and 6 music CDs per week. Scant clinical attention has been paid to (a) Rampton Hospital patients' reading interests (other than as part of an educational assessment) or (b) the potential that library services may offer in providing information to patients.

\section{Method}

We evaluated use of the library service at Rampton Hospital by taking a cross-sectional view of patients' library use in a 12-month period between July 2009 and June 2010. This involved collating information on patient book choices (including the kind of reading material, e.g. subject matter, fact or fiction, graphic novels) and details of a patient's ward and clinical unit. Patient details were otherwise anonymous. The study was a service evaluation and therefore did not require ethics committee approval. 
Table 1 Distribution of library use by specific service

\begin{tabular}{|c|c|c|c|c|c|c|}
\hline \multirow[b]{2}{*}{$\begin{array}{l}\text { Any books } \\
\text { or music }\end{array}$} & \multicolumn{6}{|c|}{$n(\%)$} \\
\hline & $\begin{array}{l}\text { Mental illness } \\
\quad(n=126)\end{array}$ & $\begin{array}{c}\text { Personality } \\
\text { disorder }(n=58)\end{array}$ & $\begin{array}{c}\text { Intellectual } \\
\text { disability }(n=47)\end{array}$ & $\begin{array}{l}\text { Women's } \\
(n=44)\end{array}$ & $\begin{array}{l}\text { Peaks, personality } \\
\text { disorder }(n=51)\end{array}$ & $\begin{array}{c}\text { Total } \\
(n=326)\end{array}$ \\
\hline Yes & $80(63.5)$ & $54(93.1)$ & $38(80.9)$ & $35(79.5)$ & $49(96.1)$ & 256 (78.5) \\
\hline No & $46(36.5)$ & $4(6.9)$ & $9(19.1)$ & $9(20.5)$ & $2(3.9)$ & $70(21.5)$ \\
\hline Books only & $17(13.5)$ & $5(8.6)$ & 7 (14.9) & $7(15.9)$ & $6(11.8)$ & 42 (12.9) \\
\hline Music only & $18(14.3)$ & $3(5.2)$ & $11(23.4)$ & $6(13.6)$ & $2(3.9)$ & $40(12.3)$ \\
\hline
\end{tabular}

\section{Results}

We collected information for 326 patients across all five clinical services and covering all 28 wards. Almost $79 \%$ $(n=256)$ used the library service in some way, $66 \%$ borrowing music, $67 \%$ borrowing books and some borrowing both. Distribution of library use by specific service is shown in Table 1.

There was significant variation in terms of library use, for example whereas around $80 \%$ or more of patients in the male personality disorder, women's and learning disability services used the library, only $63.5 \%$ of mental illness service patients did so. There was also considerable variation by individual ward, one mental illness ward having only $29 \%$ of patients using the library, whereas others within the personality disorder and Peaks units having $100 \%$ of patients using the library.

Factual books were most popular (86\% of users) compared with fiction ( $62 \%$ of users). There were slight variations in fiction borrowing by directorate/service with women patients borrowing the most fiction and mental illness directorate patients the least. Use of graphic novels was surprisingly high (17\%), 'talking books' were popular (22\%) as were self-help books about mental disorder (20\%) or about health and well-being $(17 \%)$. The most popular fiction authors were Martina Cole, JK Rowling, Stephen King, Andy McNab, Stephanie Meyer and James Patterson. Several of these authors figure on general lists of bestselling authors. ${ }^{1}$ There were some perhaps predictable items borrowed, such as Ken Kesey's One Flew Over the Cuckoo's Nest $^{2}$ and adapted scripts from the television series Porridge, ${ }^{3}$ as well as some more surprising such as Witch School: Leading the Wiccan Life. ${ }^{4}$

Contrary to expectation, borrowing of books with subjects that could be regarded as unsuitable in a high secure setting (e.g. 'true crime' or books describing martial art techniques) was relatively rare (6\% of patients who borrowed books), although the library staff have increasingly attempted to 'screen-out' such subject areas, which may have therefore limited such choices. The hospital chaplaincy department raised concerns about the content of one graphic novel.

\section{Discussion}

\section{Main findings}

The main finding is the high rate (almost 80\%) of library use by patients at Rampton Hospital. Although we have used book-borrowing as a proxy measure of actual use, it is possible that some patients also use the library for browsing purposes without active borrowing. The issue of library services is topical with the Department for Culture, Media and Sport issuing a statement explaining the government's position on some proposed library closures in the community. ${ }^{5}$ Direct comparison with public library use is limited but the proportion of adults who visited a public library in a year within the East Midlands (in 2009/2010) was about $43 \%{ }^{6}$ However, in contrast to the public, patients' library use at Rampton Hospital may be increased as they use the library to gain information that the wider public would get from, for example, using the internet.

\section{Implications}

There are some other interesting themes with possible clinical or service implications.

\section{Variations in library use}

Variation in library use by ward may be as a result of ward procedures (e.g. staff availability), which needs to be addressed to ensure equity of access for patients. In some cases patient access to books or music may be limited by scheduling clashes, problems in escorting or patients being physically or mentally unwell (including being in seclusion). The librarian piloted a type of outreach service to some women's wards, although replicating this or providing a traditional 'trolley service' elsewhere would be difficult to undertake more widely in such a geographically dispersed site within current or dwindling resources.

Fewer patients in the male mental illness (predominantly psychosis) service used the library for books or music. This may reflect clinical issues, such as reduced motivation, relating to psychotic illness. Anecdotal patient accounts to library staff have also highlighted problems with concentration, due to a range of mental conditions or perhaps medication, in inhibiting reading, which is something for treating clinicians to be mindful of. A high proportion of patients with an intellectual disability, despite likely issues with literacy, used the library, often borrowing illustrated books as well as music.

\section{Literacy issues}

It seems likely that literacy problems are an issue for forensic patients as they are for offender groups generally. ${ }^{7}$ A Prison Reform Trust (2008) study suggested that almost half of prisoners have a reading level at or below Level 1 
(equivalent to a reading age of 14 and regarded as a 'functional' skill level to complete daily living tasks independently with confidence), potentially affecting learning and employment prospects. ${ }^{8}$ Patient literacy is assessed routinely across the hospital. For example, in the Rampton Hospital Peaks (personality disorder) unit 26 (59\%) of the 44 assessed patients in 2010 had a literacy level at Level 1 or below. This can also be important since patientoriented material has been found to often require a reading age of at least age 14, with poor reading skills being a feature of mental illness as well as intellectual disability. ${ }^{9}$ Attention to and assessment of likely literacy issues among forensic patients would be useful as a prequel to potential interventions to improve wider 'functional' living skills.

\section{Choice of subject matter}

Initial concerns that patients would have lurid, salacious or abnormal interests appeared relatively unfounded. Subject areas such as 'true crime' books are no longer available in the hospital library and could only be borrowed from other libraries on request where this was not picked up by staff as unsuitable. However, there are sometimes queries for librarians over subjects that might be seen to have a forensic or security context such as martial arts or interest in the Holocaust when some brief clinical contextual advice might be helpful. The content of some graphic novels, however, has been questioned because of violent depictions. Although patients should probably be free to choose their reading choices in an unrestricted fashion (as in the community), some occasional clinical oversight might be helpful in alerting clinicians to their patients' inner worlds. Interestingly, the most borrowed fiction authors mirrored those authors who often feature in generic best-selling lists.

A significant proportion of patients used self-help books regarding mental health problems or borrowed books about general health and well-being. Although not surprising at one level it suggests an appetite for greater education about mental health that could also be targeted at an individual or ward level. Linking health information through libraries is not novel. For example, in an Australian general practice, health literature available for borrowing by patients was reported to increase health knowledge and reduce anxiety among patients. ${ }^{10}$ However, in 2005 the Department of Health commissioned the community-based Health Link pilot ${ }^{11}$ on the basis that public libraries could have a role in supporting patients in accessing information about hospital choice but the initiative had low take-up. 'Books on prescription' schemes have been set up by several primary care trusts in conjunction with local library services to provide selected material to aid patients' understanding of mental health issues and treatments. ${ }^{12}$ Consideration should be given to the use of further (selfhelp) health-related material for patients in the library with the guidance of clinicians.

Other forms of 'bibliotherapy' being more widely practised include the use of creative literature, promoted mainly through reading groups and reading development approaches, as the therapeutic benefits of reading and listening to fiction and poetry are recognised. ${ }^{13,14}$ Fiction is frequently recommended informally by library staff and shared with patients in reading groups along with poetry and play reading. The use of reading therapy could be developed with a more structured approach where clinicians working together with library staff and other health professionals introduce carefully selected material to aid the recovery of patients. This has been undertaken with patients with intellectual disability at Rampton following the approach described elsewhere. ${ }^{15}$ Also, the Reader Organisation's Get Into Reading has provided initiatives such as a Reader-in-Residence project with Mersey Care NHS Trust running facilitated groups in mental health wards, day hospitals and community settings including Ashworth high-security hospital. ${ }^{16}$

The relative popularity of 'graphic novels' (17\% of our patients) may reflect patients' struggles with literacy but is probably related to the increased general popularity of this genre. This format could provide a vehicle not just for leisure but also in combination with useful information about common medical, including psychiatric, morbidity. The increase in medical graphic novels was described recently in The Guardian ${ }^{17}$ and included examples such as former psychiatric nurse Darryl Cunningham's Psychiatric Tales. $^{18}$

\section{Potential service development}

This study has suggested to us some potentially useful ideas involving reading material and library facilities. For example, for patients in long-term seclusion or segregation the use of a 'talking book' broadcast through their door could be of benefit in enhancing their interests or distraction when possessing reading materials, because of the risk, may not be possible. Similarly, it may be that factors that the general public regard as enhancing their library experience ${ }^{19}$ such as a good range and choice of books, friendly and knowledgeable staff and a pleasant library environment (including a coffee shop) are also factors that our patients value. This could be determined by a more formal user survey. Other 'outreach' ideas such as setting up reading groups (already a feature of some directorates, such as in the women's service and Peaks unit) or encouraging patient book or music reviews or a 'poetry corner' could be beneficial in encouraging further book use, enhancing literacy skills and developing reading as therapy. The library is valued by its service users and should also 'be considered in terms of contribution to clinical care, not an additional extra only for recreational purposes'. ${ }^{20}$

\section{Findings from other research}

Other hospital-based secure services have considered library use by its consumers. For example the Scott Clinic Medium Secure Unit within Mersey Care NHS Trust undertook a survey of its service users' library needs in 2009 (C. Payne, personal communication, 2009) after they noted the library was underutilised. Problematic concentration was a significant theme in impairing reading and there was a preference for visual and factual books rather than fiction, with an emphasis on books that were quick to read. A barrier to library use from the patient's perspective was a worry that borrowed items might get lost or stolen. The Knowledge \& Library Service within Mersey Care NHS Trust took steps to adjust the collections and the 
way the service was promoted as a result. In addition, for 8 months from June 2009 the library manager at Ashworth Hospital, part of Mersey Care NHS Trust, presented records relating to patient borrowing to two care teams, and recorded the team responses. The greatest number of responses indicated that the library material demonstrated a 'healthy' interest.

However, innovation may be more about adaptation in a tighter financial climate. For example hospital efficiency savings have been added to the library budget, which is also hampered by similar local authority cost savings. Talking books, although appearing popular (particularly in the personality disorder and Peaks units) are significantly more expensive than text-based books and will probably not be able to be funded from current resources. Giving consideration to newer technologies, such as an e-reader-type approach or free audio-books available as podcasts on adapted portable media players (currently being piloted at another high-security hospital), despite some security issues and initial investment, might be a fruitful approach to more efficient use of resources in future.

\section{About the authors}

John Milton is a consultant forensic psychiatrist at Rampton Hospital, Nottinghamshire Healthcare NHS Trust. Rosemary Ruck is a librarian at Rampton Hospital, Nottinghamshire Healthcare NHS Trust.

\section{References}

1 Wikipedia. List of Best-Selling Fiction Authors. Wikipedia, no date (http:// en.wikipedia.org/wiki/List_of_best-selling_fiction_authors).

2 Kesey K. One Flew Over the Cuckoo's Nest. Penguin, 2005.

3 Clement D, La Frenais I. Porridge: The Scripts. Headline, 2002.

4 Tompkins D. Witch School: Leading the Wiccan Life. Llewellyn Publications, 2009.

5 Department for Culture, Media and Sport. Public Libraries. Department for Culture, Media and Sport, no date (http://www.culture.gov.uk/ what_we_do/libraries/3416.aspx).
6 Department for Culture, Media and Sport. Taking Part: The National Survey of Culture, Leisure and Sport. Adult and Child Report. Department for Culture, Media and Sport, 2010 (http://www.culture.gov.uk/ publications/7386.aspx).

7 Clark C, Dugdale G. Literacy Changes Lives. The Role of Literacy in Offending Behaviour. A Discussion Piece. National Literacy Trust, 2008 (http://www.literacytrust.org.uk/assets/0000/0422/Literacy_changes_ lives_prisons.pdf).

8 The Prison Reform Trust. June 2008 Factfile. Prison Reform Trust, 2008.

9 Gralton E, Sher M, Lopez CD. Information and readability issues for psychiatric patients: e-learning for users. Psychiatrist 2010; 34: 376-80.

10 Charlton I. Usefulness of a patient library in a suburban general practice. Med J Aust 1997; 167: 579-81.

11 Creaser C, Harrison J, Lockyer S. Patient Choice Public Library Pilot Evaluation Report Summary. LISU, 2008 (http://www.healthlinklibraries. co.uk/pdf/Patient_Choice_evaluation_summary.pdf).

12 Hicks D. An Audit of Bibliotherapy/Books on Prescription Activity in England. Prepared for the Arts Council. Reading Agency, 2006.

13 McArdle S, Byrt R. Fiction, poetry and mental health: expressive and therapeutic uses of literature. J Psychiatr Ment Health Nurs 2001; 8: 517-24.

14 Morrison B. The reading cure. The Guardian 2008; 5 January (http:// www.guardian.co.uk/books/2008/jan/05/fiction.scienceandnature/ print)

15 Cocking A, Astill J. Using literature as a therapeutic tool with people with moderate and borderline learning disabilities in a forensic setting. Br J Learn Disabil 2004; 32: 16-23.

16 The Reader Organisation. Get Into Reading. The Reader Organisation, no date (http://thereader.org.uk/get-into-reading/health-and-wellbeing/).

17 O'Luanaigh C. My favourite medical graphic novels. The Guardian 2010 19 July (http://www.guardian.co.uk/science/blog/2010/jul/16/ favourite-medical-graphic-novels).

18 Cunningham D. Psychiatric Tales. Blank Slate Books, 2010.

19 Ipsos MORI, Social Research Unit. What do the Public Want from Libraries? User and Non-User Research - Full Research Report. Ipsos MORI Social Research Unit, 2010 (http://www.mla.gov.uk/news_and_views/ press_releases/2010/ /media/Files/pdf/2010/research/What_do_ the_public_want_from_libraries).

20 Fanner D, Urquhart C. Bibliotherapy for mental health service users. Part 2: a survey of psychiatric libraries in the UK. Health Info Libr J 2009; 26: 109-17. 